\begin{tabular}{|c|c|c|}
\hline 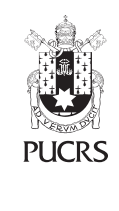 & $\begin{array}{l}\text { ESCOLA DE } \\
\text { HUMANIDADES }\end{array}$ & $\begin{array}{l}\text { Revista de Filosofia da PUCRS } \\
\text { Veritas, Porto Alegre, v. 65, n. 1, p. 1-11, jan.-mar. } 2020 \\
\text { e-ISSN: } 1984-6746 \text { | ISSN-L: 0042-3955 }\end{array}$ \\
\hline de) $h t t p: / / d x$ & $\mathrm{rg} / 10.15448 / 1984-6746.2020 .1 .36050$ & \\
\hline
\end{tabular}

ENTREVISTA

\title{
Entrevista basada en la conferencia del Rabino Dr. Fishel Szlajen, "Inteligencia Artificial y Transhumanismo: falacias del humano exacerbado y desfondado en la tecnologia", en el IV Coloquio de Bioética de la PUCRS (2019)
}

\section{Evandro Pontel ${ }^{1}$ \\ orcid.org/0000-0002-9659-4231 \\ epontel@hotmail.com}

\section{Ricardo Ronchetti ${ }^{2}$}

orcid.org/0000-0003-0436-0970 ricardo.ronchetti@hotmail.com

Recebido em: 06 jan. 2020 Aprovado em: 17 jan. 2020 Publicado em: 12 mai. 2020

\section{(c) (1)}

Artigo está licenciado sob forma de uma licença Creative Commons Atribuição 4.0 Internacional.
Fishel Szlajen es Rabino y Doctor en Filosofía, Master en Filosofía Judía y Mandel Jerusalem Fellow. Se desempeña como Miembro Ordinario de la Pontificia Academia para la Vida (Vaticano), Profesor de Postgrado en Bioética en la Facultad de Derecho (UBA) y en Metodología de la Investigación (UNLaM). Director del Depto. de Cultura en AMIA y Vicepresidente del CONABI (Comité Nacional de Bioética). Ha sido galardonado en el 2018 con la máxima distinción que otorga el Senado de la Nación Argentina, "Mención de Honor Domingo F. Sarmiento", por su contribución académica a la sociedad; y ha sido destacado en el 2019 por la Legislatura de Buenos Aires, como "Personalidad Destacada de la Ciudad Autónoma de Buenos Aires en el ámbito de la Cultura". Posee más de 100 publicaciones entre papers, artículos y libros en su área de investigación, la Filosofía Judía Aplicada, focalizado en la bioética.

Rab. Dr. Fishel Szlajen ¿Cómo define el Movimiento Transhumanista y cuál es su vínculo con el posthumanismo?

Sabido es que el alto desarrollo tecnológico contemporáneo es transversal a las nacionalidades, etnias, ideologías, religiones e idiomas transformando los medios en las relaciones humanas y con el mundo en todos sus aspectos. Pero desde hace unos años, algunos pretenden o pronostican la utilización de la tecnología para cambiar las propias características humanas, mediante el llamado transhumanismo, término acuñado en 1957 por el darwinista Julian Huxley. Un movimiento que sostiene los actuales albores de una nueva fase evolutiva de la humanidad, en la cual se fusionan los humanos con las máquinas transformándolos en una especie híbrida, un proyecto de diseño, aumentando y adicionando capacidades humanas deviniendo en un posthumanismo, como fase consolidada a nivel masivo de dicha eventual mejora. 


\section{¿Cuál es su concepción respecto de este movimento y el punto de encuentro con la biotecnología de una manera positiva y construtiva?}

Esta idea de mejora continua en el hombre tiene origen biblico, y radica en trascender su animalidad habilitando su humanidad como diferencia esencial entre otros seres, cuya unicidad es su capacidad de ser preceptuado por una autoridad fuera de sí mismo y su medio. Es decir, un ser habiente de voluntad como facultad que posibilita conscientemente contrariar la propia naturaleza, deseo o pulsión, respondiendo a una alteridad como autoridad o valor. En este sentido, si bien el perro desea un trozo de carne, no es consciente que lo está deseando, y por ello no puede cancelarlo por motu proprio, excepto bajo adiestramiento. Es decir, carece de voluntad. Y si de tecnología se trata, el episodio del siglo Il e.c., donde el gobernador romano de Judea, Quintus Tienius Rufus provoca a Rabi Akiva preguntándole si las obras de Dios son más grandes que las del hombre, y cuya respuesta, las del hombre, mostrándole un grano de maíz y una torta, expresa la favorable visión en la cultura biblica para producir y desarrollar mejoras cuando su propósito se orienta axiológicamente. Mismo sabio que sobre la circuncisión respondió que los bebés no nacen circuncisos con el sólo propósito de refinar nuestro carácter cumpliendo con aquel precepto. Y desde ya esto incluye el beneplácito tecnológico para tratar patologías, incluso bajo intervenciones genéticas, curar lesiones y fortalecer aquellas debilidades producto de anomalias, incluso estéticas.

Biblica y filosóficamente la estrecha relación entre naturaleza y humanidad, radica en el esfuerzo del hombre en controlar la suya propia, interna, así como también operar con la externa, el medio que lo rodea. Esta es la relación que desde la Biblia le otorga un significado religioso a los actos, y desde la filosofía uno moral. Aristóteles mismo relaciona la felicidad con la sabiduria práctica y filosófica, acompañada o no del placer; e incluso Kant la define como el estado de un ser racional cuya existencia es según su voluntad. En ambos, la felicidad subordina la propia naturaleza humana a la concepción del Sumo Bien, como sintesis de virtud. Pero aclarando que cuando la voluntad está orientada a la consecución incluyo de aquellas virtuosas definiciones de felicidad, puede la conducta no ser moral. Es decir, si bien puede ser conforme al deber, no necesariamente por deber.

Así, de ninguna forma la tecnología debe alienar al hombre respecto de la naturaleza, destruyendo mediante tendencias nihilistas aquella relación bíblico-filosófica de superación. Por cuanto conllevaría la propia destrucción del hombre. Dicha alienación se patentiza ya en un planeta con gravisimos problemas climáticos, de contaminación y desigualdad e incluso demandando el hombre mayores derechos, pero a su vez preocupado por desarrollar e implementar tecnologias deshumanizantes y produciendo élites como nuevas clases sociales por quienes accederian a estas hibridaciones o ingenierías genéticas.

$Y$ esto sucede con el transhumanismo, el cual únicamente focaliza en el avance de las capacidades operativas humanas, su externalidad, no siendo sino una radical secularización nihilista de aquella bíblica demanda de mejora continua, dado que ofrece una visión vacía de contenido y finalidad en la búsqueda de perfección operativa. Tan sólo imagina la obsolescencia planificada de la humanidad como una especie biológica predicando una ruptura abrupta de la historia, mediante la hibridación y la inteligencia artificial. Aquello que Raymond Kurzweil, Jurgen Schmidhuber y Yuval Harari, entre otros grandes exponentes del trans o posthumanismo. denominan singularidad. El explosivo cambio radical, repentino y definitivo donde el homo sapiens es reemplazado por el homo cyborg $u$ homo deus. Un concepto de perfección operativa y felicidad utilitaria, todo reducido a la eficacia cuantitativa operacional y al cálculo dolor versus placer, mediante ingeniería genética y aditamentos cibernéticos. Un subjetivo materialista estado mental o de perfeccionamiento instrumental carente de todo sentido de teleología trascendente o integridad moral. 
En su opinión ¿pueden estar ausentes la religión y la filosofia en toda posibilidad que el hombre transcienda su naturaleza a través de la tecnologia o que la Inteligencia Artificial reemplace al hombre?

La respuesta es un contundente no, porque el problema radica precisamente en dicha errónea idea, por la cual se cree que el hombre puede transcender su naturaliza animal mediante la tecnologia, o bien la tecnologia reemplazar al hombre como tal, cuando en verdad lo que hace es exacerbar su parcialidad. Ya desde la Bíblia se desarrollan dos concepciones del ser humano. La primera en Génesis 1:27-30, cuando es creado simultáneamente varón y mujer, sin explicar su proceso y comandándolo a dominar y sojuzgar el mundo; mientras que en la segunda, en Génesis 2:7-23. Dios forma primero a Adam del polvo de la tierra, insufla en su nariz hálito de vida y luego de Adam es creada Javá como su compañera, comandándolos a cultivar y mantener el Jardín de Edén. Noéticamente, esta dualidad distingue dos tipologías humanas tal como lo indica Yosef Soloveitchik. La primera, empoderándose del mundo exterior y controlando las fuerzas naturales, deviniendo en un ser tecnológico, interesado en duplicar funcionalmente la dinámica de la realidad disponiendo de ella a voluntad y servicio. Un ser utilitario cuya pregunta es ¿cómo funciona el mundo? y caracterizado por la dignidad adquirida a partir de la conquista y elevación existencial por sobre la naturaleza. La segunda, contemplando receptivamente el mundo tal como le es dado, en sus dimensiones originales, y bajo el interrogante de ¿quién es? o ¿por qué la existencia? Un ser habiente de una experiencia esencial, no identificado con lo sensorial hedonista, ni con el pensar cartesiano ni el racionalismo kantiano y menos con el sufrimiento schopenhaueriano; sino logrando un modo de vida disciplinado acorde a su separación de la naturaleza y dominado por el Creador. Un ser humano cuya especificidad es la redención por la cual adquiere su noción ontológica manifiesta en su seguridad axiológica. Ambos humanos son intrigados por el cosmos.
El primero va en busca de su control y poder, cuya dignidad redunda en una técnica de vida, en el respeto y la atención del otro mediante habilidades de acción; razón por la cual es creado hombrey mujer simultáneamente, dado que no hay dignidad como categoría conductiva en el anonimato o en soledad, sino en la capacidad de hacer sentir su presencia o impacto medido por sus logros en la exterioridad. El segundo, busca su propia cualidad ontológica en lo profundo de su persona encontrando la redención a través de la capitulación, del retiro, y por ello, sólo mediante el sacrificio, entregando parte de sí mismo, halla su compañera, Javá. Su control y poder es sobre sí mismo, cuyo éxito consiste en el movimiento de retroceso. Este humano es formado del humus, emergiendo humilde y solitario en su origen, sin necesidad de mostrar, de comunicar, ni de una existencia extrovertida.

Actualmente, el desbalance entre ambas bíblicas tipologías en el ser humano. desnaturalizándolo, se ha inclinado hacia la exacerbación de la dignidad en detrimento de la redención, transformando la conquista fenomenológica en noción ontológica, y destruyendo la integridad humana por cuanto el desentenderse de una parte no hace que ésta desaparezca constituyendo la otra parte un nuevo todo, sino sólo se transforma en más parcial.

Esta parcialidad humana exacerbada se manifiesta en múltiples dimensiones. Desde las esferas del poder, este humano exacerbado es quien puede representar momentáneamente el pensamiento, pero no soporta el examen. Es el snob que puede ocupar durante un corto tiempo cualquier rol sin diferenciarse de quien es habiente del perfil. Desde lo político-legislativo, el humano exacerbado se conduce como si cualquier medida, por absurda que sea, pudiera imponerse a un pueblo con la sola suficiencia en el número de voces para convertirla en ley. Incluso pretendiendo que la naturaleza sea democrática o susceptible de ser engañada o abolida por la insolencia de la presuntuosidad o el pretensioso antojo. Sólo logrando embrutecer al ser humano, pero haciéndole creer que accede a una inteligencia o estadio superior. Pero también 
desde el llano, es quien ante algún aspecto de la persona, como el menor arco, lo transpola integramente a toda ella, como completando por si mismo la curva; y al levantar el velo que parecía ocultar aquella personalidad o figura, se ofende por no hallar sino alguien contrahecho o aquel fragmento. En términos colectivos, la sociedad exacerbada es aquella que representa ciertas virtudes, pero que en sus individualidades no se encuentran las variables que las constituyen. En las relaciones interpersonales, la exacerbación se manifiesta en interlocutores que se expresan asimétrica e imperfectamente, ninguno escuchando demasiado al otro; o bien en un público que sólo debe escuchar y no hablar. pero que de todas formas juzga lo equivocados y torpes que resultan los polemistas. En el sujeto mismo, esta exacerbación se manifiesta como habiente de una conciencia pre-reflexiva e impersonal, que sugiere la posibilidad de hacer y deshacer lo que se desee, revistiéndolo luego de justificaciones racionales cuando las haya o bien, y ante su carencia, formulando falacias y tergiversaciones de la propia realidad.

Y por supuesto la exacerbación desde la biotecnología, done el hombre ejerce su potestad irresponsablemente para consigo mismo y su prójimo, donde la ciencia y la tecnología, pudiendo dedicarse a resolver hambrunas, patologias u otras dolencias, se han enseñoreado en la licenciosidad humana.

Un aspecto de dicha exacerbación se hace patente concibiendo el cerebro desde el tan vigente funcionalismo, como un sistema complejo de transmisión y procesamiento de información constituido por múltiples partes interconectadas. Cuestión que no es verdad sino tan sólo en una pequeña parte, la fisiológica. Pero se utiliza dicho modelo porque permite fácilmente compararlo con una computadora pudiendo llegar a decir que ésta posee mente o alma. $Y$ aquí se hace patente la ya mencionada transformación de la conquista fenomenológica en noción ontológica destruyendo la humanidad como integridad, creyendo que desentenderse de una parte hace que automáticamente esta desaparezca constituyendo un nuevo todo, pero en verdad no es sino una exacerbación de la parcialidad. No obstante, si bien el funcionalismo resuelve más fácil el problema de describir el cerebro como un conjunto de funciones y por ello pasible de ser emulado cibernéticamente, desde la perspectiva del problema más dificil, que es la posibilidad de conseguir de la máquina una mente o alma, una conciencia, ninguna de los intentos más relevantes hasta ahora pudo lograrlo.

En este sentido, el test de Alan Turing ya en 1950 consistía en una máquina que exhibiera un comportamiento inteligente similar al de un ser humano o indistinguible de este, implementado mediante una conversación únicamente textual mediante un teclado y un monitor y donde el evaluador no pueda distinguir entre el humano y la máquina luego de cinco minutos de conversación. No obstante, esta prueba no evalúa el conocimiento de la máquina en cuanto a su capacidad de responder preguntas correctamente, sino que sólo toma en cuenta la capacidad de la máquina de generar respuestas similares a las que daría un humano. Más aún, en el hipotético caso que pudiéramos imaginar una máquina con conciencia como realidad psíquica, ya se ha demostrado que por la propia cualidad de la conciencia, la cual pertenece como toda realidad psiquica al dominio privado, dada única e inmediatamente sólo para el habiente de dicha conciencia, resulta imposible saber si la máquina la tiene o no. Y el hecho que cualquiera de nosotros podamos inferir que nuestro prójimo es habiente de la misma conciencia, no es algo demostrable sino intuitivo y por interacción espontánea, cuyas conductas son más o menos las similares a las nuestras. También está el caso del algoritmo llamado Eliza, diseñado por Joseph Weizenbaum en 1966, emulando una ayudante terapéutica cibernética, quien bajo la escuela de Karl Roggers, no era otra cosa que un programa diseñado para captar determinados vocablos o expresiones que el paciente emitia para responder con otras prediseñadas. Si bien en este caso también podría considerarse que sus respuestas eran inteligentes, eso no quiere 
decir que dicho algoritmo sea una mente. Caso similar el programa llamado Parry, diseñado por Kenneth Colby en 1972, el cual simulaba el comportamiento de un esquizofrénico. $Y$ aquí es relevante la diferencia entre lo inteligente y lo consciente, aspectos que el funcionalismo ha deliberadamente omitido, considerando que las realidades psíquicas no son más que el fruto y conducta de un número ingente de neuronas, descartando la conciencia humana como la percepción responsable y personal de la propia existencia, estados y actos, pretendiendo asemejarla a un algoritmo de identidad. Y es precisamente esto lo atractivo aunque falaz del funcionalismo. Describir la mente no como una cosa sino como un proceso analogándolo a un reloj. Es decir, para saber qué es un reloj poco importa su estructura y material, así como tampoco sus componentes, peso, volumen, o donde se emplaza, sino que lo importante es qué hace. Y lo que hace es mostrar la hora. Es decir, cuál es su función. Pero esto tiene el inconveniente de no distinguir la sintaxis de la semántica, al igual que Eliza, la ayudante terapéutica cibernética. Dicha diferencia ya fue contundentemente demostrada mediante la denominada "habitación china", refutando la creencia que el pensamiento puede reducirse al cálculo, a la computación. La mente implica no sólo la manipulación y procesamiento de simbolos (gramática o sintaxis), sino que además posee la capacidad semántica para darse cuenta o estar consciente de los significados de aquellos símbolos. Pero esta capacidad semántica, no es un algoritmo, ya que una máquina realiza acciones físico-electrónicas sin entender lo que hace y el por qué lo hace. Esta "habitación china" consta de un ejercicio en el cual nos introducimos en una computadora completamente aislados del exterior, salvo por una ranura para hojas de papel por la que entran y salen textos en chino. Fuera de la sala o computadora, se encuentra un chino que cree que la computadora entiende su idioma, pero en verdad somos nosotros que no sabemos una sola palabra en chino pero estamos equipados con manuales y diccionarios que indican las reglas que relacionan los caracteres chinos con los latinos. Esto es, "Si entran tal y tal caracter, escribe tal y tal otro". De este modo nosotros manipulamos los textos en chino que entran por la ranura y seremos capaces de responder a cualquier texto introducido ya que el manual que poseemos con las reglas del idioma nos indica las correlaciones. El chino en el exterior creerá que sabemos su idioma, aunque es falso. Y seguirá siéndolo aun cuando las traducciones o respuestas se perfeccionen con la práctica y la realimentación de información por los usuarios chinos que advierten y notifican los errores cometidos. Dado que lo único que estaremos haciendo es perfeccionar el manual de cálculo y operación en la conversión de caracteres. Pero eso no es saber el idioma. Eso no es pensamiento sino cálculo. No es semántica sino sintaxis. En otras palabras, el pensamiento no migra de un soporte biológico neuronal a uno cibernético electrónico, y comportarse similarmente a una persona no implica ser persona.

\section{¿En qué sentido la religión y la filosofía aportan a la problemática de la cibernética como trascendencia del hombre por la máquina?}

En principio no hay que confundir trascendencia con el desarrollo y avance tecnológico que imprime nuevas formas y modos comunicacionales y laborales, donde algunos procedimentos y ofícios quedarán obsoletos y se desarrollarán otros, tal como siempre ocurrió a través de la historia. Ahora, si profundizamos respecto de la trascendencia del hombre respecto de la máquina, tal como expuse en la pregunta anterior, resulta necesario recordar la afirmación de Karl Popper por la cual toda la filosofía occidental gira alrededor de su más dificily profundo problema, la relación cuerpomente. Dos mundos, uno externo y otro interno. Uno constituido por sustancias y energías más sus interacciones y procesos, pudiendo ser conocidos objetiva y públicamente. El otro, constituido por realidades psiquicas como conceptos, ideas, sentimientos, deseos, anhelos, recuerdos, dolor, ánimo y esperanzas, conocidos sólo subjetiva 
y privadamente por la misma persona que los experimenta. Asi, el cerebro pertenece al mundo objetivo, de dominio público, sujeto de investigación cientifica y donde todos saben igualmente de su cerebro como del de otro. A diferencia de las realidades psiquicas, pertenecientes al dominio privado, individual y por ello no siendo pasible de ciencia. Y desde la causalidad, esta rige tanto para lo físico, producto del devenir de otros anteriores, pero siempre dentro del mismo dominio; como para lo psíquico al recordar un hecho que deviene en tristeza, alegría o nostalgia, un concepto que surge de otro, o el hambre al pensar en comida. Pero entre los mundos fisicos y psíquicos hay una incompatibilidad causal interactiva, ya que de lo contario ninguno de ambos serian tales, aun cuando se vivencien reacciones concomitantes o reciprocas.

Descartes distinguió dualmente lo extenso y la razón, postulando que si bien el cuerpo está estrechamente unido alyo, mi pensamiento por el cual soy lo que soy, es entera y verdaderamente distinto de mi cuerpo pudiendo ser sin éste. Pero Spinoza contrariamente postula la unicidad de cuerpo y mente, convirtiendo éstas en atributos de una mónada, la cual es conocida aunque no constituida, por su extensión como cuerpo y el pensamiento como idea. Luego Leibnitz da cuenta de la falta de explicación en ambos filósofos, de la relación entre cuerpo y mente. por cuanto lo que sucede en uno ocurre con independencia de la realidad del otro, dado que el cuerpo sólo puede moverse por factores materiales y el pensamiento sólo por ideas. Si bien desde lo intuitivo, el hecho de querer hablar o escribir pareceria motorizar el conjunto de órganos que resultan en palabras o escritura, aquellas querencias no tienen relación alguna con los procesos físico-químicos del cuerpo que la actualizan. De hecho, el cuerpo funciona ausente de la realidad psíquica tanto como los riñones o el hígado de quien está enseñando historia.

Y así, el fisicalismo reconociendo sólo la realidad física, el idealismo reconociendo sólo la psíquica o el dualismo, siempre fueron aporéticos. Incluso el fisicalismo, en los trabajos de John Smart, reconoció que las realidades psíquicas son fenómenos excepcionales a las categorias físicas; y desde la neurofisiologia, Charles Sherrington ha reconocido que ante el problema psicofísico no hay preferencias entre monismo y dualismo. Tampoco el epifenomenalismo encuentra una respuesta, sino que la parcializa unidireccionalmente donde lo físico-químico exhibe en lo psíquico como el proyector de cine en una pantalla, y donde las imágenes (lo psíquico) no influyen en el proyector (lo físico). Más, asi como una imagen no causa la siguiente sino por el proyector, tampoco entre las realidades psiquicas sino por los procesos fisicoquímicos cerebrales como fenomenologia real y causa de aquellas como su proyección.

Hoy la cibernética emula la fisiología mediante procesadores pretendiendo asemejarse al pensamiento, aunque la designación "inteligencia artificial" es inadecuada en contenido y metodología. Y aqui es adecuado distinguir, tal como lo hace Wilhelm Dilthey, explicación de comprensión, donde la primera es la capacidad de incluir el fenómeno dentro del marco de otros ya conocidos mediante similitud de relaciones funcionales; mientras que la segunda intenta concebir el fenómeno mismo. Luego, la relación explicativa entre un recuerdo y la tristeza es funcional, pero distinto de la comprensión de la tristeza o el recuerdo en si mismo, cuya ignorancia impide al sujeto conocer su realidad psíquica. A diferencia del total entendimiento de una máquina por la explicación funcional de sus partes, sin que el técnico necesite saber la naturaleza de aquellas. El hombre, al pensar, quiere entender su pensamiento y no sólo saber la relación funcional entre los procesos psiquicos que le acontecen. Más, para la computadora toda pregunta y respuesta debe ser formalizada en partes relacionadas lógicamente y divisibles en cantidades elementales. Pero el pensamiento humano abarca problemas no reductibles binariamente, dado que las realidades psíquicas no son formalizables.

Preguntar por relaciones entre distancias es radicalmente distinto a preguntar sobre la relación entre el significado de la valoración de la fidelidad y el temor reverencial a Dios. La primera, científica, con los datos necesarios resulta en un 
número, pero no asi la otra no pudiendo nutrir a la computadora con información sobre la valoración humana en dichas cuestiones. Es decir, la computadora puede eventual y parcialmente ser desde el funcionalismo un modelo del cerebro pero no de pensamiento, no pudiendo analogarlo al proceso electromecánico de la computadora, así como tampoco la memoria informática es la humana por no tener consecuencias en las realidades psíquico-emocionales de su sujeto. Una máquina sin uno de sus componentes no ejecuta o falla en un determinado accionar. mientras que el cerebro ante ciertos daños su función atribuida es suplida; similar al ajedrecista que aun con menos piezas que su rival logra ganar, dado que en desventaja juega sus piezas restantes de forma distinta a como lo hubiera hecho con todas. Claramente, el funcionamiento del cerebro es cuestión de fisiología pero no así el del habiente de cerebro, donde ocurren los procesos y realidades psíquicas a cuenta de lo que ocurre en el cerebro.

De hecho, el dualismo computadorausuario evidencia que la primera ejecuta solo la actividad físico-electrónica, y cuyo resultado en caracteres sólo tienen sentido o significado respecto del hombre usuario habiente de conciencia e inteligencia. Así, incluso concibiendo la computadora como modelo de cerebro, el usuario de la computadora es como el sujeto habiente de cerebro. La computadora nunca ejecuta una operación matemática o lógica, sino sólo actividades físicas predeterminadas por el usuario que la piensa e interpreta. Toda relación lógica entre componentes y caracteres de la computadora no existe sino en la conciencia de su programador humano. En definitiva, la computadora no piensa sino que necesita de su usuario manifestando asi la dualidad entre el aspecto objetivo fisiológico operativo y el aspecto subjetivo psíquico interpretativo. Porque el pensamiento no es un conjunto de funciones cerebrales o cibernéticas fuera del sujeto o usuario consciente, similarmente a una melodía que no es un conjunto de sonidos o vibraciones fuera de la conciencia o sentido musical de quien la escucha.
Por ello, la cibernética no construyó una modelo de pensamiento sino en el mejor de los casos un parcial e insatisfactorio modelo de cerebro. Desde la filosofía, 2500 años atrás los griegos se preguntaron sobre la relación entre la mente y el cuerpo. Desde el judaísmo, Najmánides, Moisés Isserles y Yosef Karo, concluyeron la incomprensibilidad de la relación entre cuerpo y alma. La psicologia, a través de Cecil Mace. dictamina actualmente la imposibilidad para nuestro pensamiento de resolver el problema psicofísico, no por falta de información sino por su imposibilidad lógica. Incluso desde la fisiologia, Edgar Adrian expresó la completa incapacidad de la ciencia para describir satisfactoriamente la actividad mental. Así, no se trata de dualismos, monismos o paralelismos ontológicos, sino de una carencia epistemológica que redunda en la imposibilidad de atribuir pensamiento o inteligencia a las máquinas.

\section{¿Qué significa decir Transhumanismo como otro movimiento jacobino?}

Esa es una expresión que utilice en mi conferencia del IV Colóquio Internacional de Bioética en la PUCRS en 2019

El jacobinismo resulta en un problema netamente contemporáneo. Los jacobinos, radicalización politica de la Revolución francesa, aun inspirados en el igualitarismo de JeanJacques Rousseau, y en el garantismo y la división de poderes de Montesquieu, profesaron un rabioso anticlericalismo, se arrogaron la voluntad y la representación popular, lo que devino en un autoritarismo aterrorizante encabezado por Maximilien Robespierre, que ejecutó por tribunales populares a más de 40 mil franceses considerados enemigos de la revolución por su desacuerdo. Su consigna fue la de gobernar, al menos la sociedad francesa, imponiendo un renovado orden político totalizante con la violencia y el terror como coadyuvante, intentando producir un nuevo hombre y sociedad. Este nuclear concepto fue adoptado por diferentes líderes tal como Lenin, agravado luego con Stalin, quien, a pesar de Karl 
Marx, implementó un capitalismo de Estado al intentar construir una sociedad totalizante con "revolucionarios profesionales", principalmente de la intelligentsia burguesa, denominando a sus bolcheviques "jacobinos de la democracia social", pero conservando el proceso eleccionario como legitimador democrático de su régimen desde el pueblo (proletariado); consideraba enemigo a todo opositor, al que le aplicaba el terror para doblegar su voluntad.

Este jacobinismo esencialmente secular fue aplicado al ámbito religioso bajo la revolución iraní liderada política y espiritualmente por el ayatolá Ruhollah Khomeini, que instauró la República Islámica de Irán bajo la aprobación por votos en referéndum de una Constitución republicana y teocrática, con un esquema institucional electivo, aunque bajo el absolutismo y las órdenes del liderazgo supremo del ayatolá, combinando elementos ideológicos islámicos chiitas con estructuras democráticas modernas. Huelga mencionar sus ramificaciones en grupos terroristas que actúan en sus respectivos marcos políticos nacionales y transnacionales como Hezbollah y Hamas, más el islamismo integrista fundado a principios del siglo XIX, el wahabismo (salafismo), fuente del actual Estado Islámico de origen sunita, que acciona para implantar un yihadismo global, considerando apóstatas y susceptibles de ejecución incluso a los propios musulmanes en desacuerdo.

Lejos de una instauración de teorias socioeconómicas o tradiciones religiosas, estos son movimientos jacobinos oportunamente revestidos para justificar una pureza o un modo de vida más correcto, orientados a producir un hombre y una sociedad nueva por medios políticos modernos para su legitimación, con formulaciones de modo utópico, esencial y totalitario, ayudados eventualmente por el terror o la guerrilla, pero con las estructuras, la tecnología y los sistemas de Estados modernos paradójicamente combatidos y de hecho antitradicionalistas. Lo moderno así radica en la actual concepción de la acción política, a través del reclutamiento y la movilización militante, devenida oportunamente en terror o delito político, como fuerza activa y medio para lograr cambios sociales e individuales, adicionando el concepto del pueblo como soberano implementado en parlamentos, elecciones y constituciones que determinan el proceso y fuente de la autoridad política, aun cuando sus voluntades sean avasalladas. No se trata asi del choque entre civilizaciones de Samuel Huntington ni del fin de la historia de Francis Fukuyama, ya que los mencionados fundamentalismos son corrientes ideológicas jacobinas con diversos enclaves (idearios sociopolíticos o religiosos), pero dentro de una misma estructura política moderna que, a su vez, indica la no finalización de las luchas ideológicas, más allá del triunfo de las democracias liberales como sistema mayormente impuesto.

Com esto en mente, es posible entender que esta idea del transhumanismo no es sino otro movimiento jacobino con tendencias a producir un renovado orden político totalizante, intentando producir un nuevo hombre y sociedad. Pero ahora, en lugar de consignas político-ideológicas, los futurólogos buscan crear una sociedad perfecta desde la tecnología. Otro sueño, siempre muy seductor para quienes desean ser pioneros en un imaginario revolucionario cambio humano, pero que en el mejor de los casos es frivola, por no demandar el esforzado perfeccionamiento interno, espiritual o moral, conductivo, que indica ya desde antaño la Biblia y la filosofía. En lugar de una visión de un hombre mejorado cibernéticamente en sus capacidades operativas y hasta un supuesto vencimiento de la muerte, sería superador ocuparse en dignificar y redimir al hombre, su conducta, su hábitat, su vida, su vejez y su muerte. Pero para ello es necesario fortalecer nuestras virtudes éticas e intelectuales, para luego proseguir con una redención trascendente. Tal como el Eclesiastés y otros sabios enseñan, el hombre no se agota en la juventud eterna, el placer o su operatividad, su significado no desaparece cuando las funciones corporales disminuyen o cesan, sino que radica en su ser único constituido de materia pero dotado de conciencia y habla, que lo hace uno axiológico. 
¿Cuáles son los puntos críticos en la idea e implementación del transhumanismo - posthumanismo acorde a sus propios postulados?

Hay tres puntos críticos que hacen del transhumanismo una futurología en lugar de una realidad. El primero radica en un error conceptual, dado que una eventual hibridación hombre-máquina, una cyborización o un cambio genético artificialmente provocado, son cambios culturales y no biológicos evolutivos. Esto es, no hay un hombre post-orgánico. El segundo punto radica en la inexistencia de una inteligencia artificial, ya que tal como expliqué en las respuestas anteriores, esta es sólo un conjunto de algoritmos, distinto a una persona. Porque no es posible escindir inteligencia de conciencia, dado que ésta como percepción responsable e individual de la propia existencia, estados y actos, es la realidad psíquica base de aquella. Y no pudiendo asemejarla a un algoritmo, el cual podrá traducir textos, jugar ajedrez o diagnosticar patologías, similar a un humano, pero no es sino un resultado de escanear millones de casos y calcular estadísticamente la mejor opción para cada circunstancia. La denominada inteligencia artificial no es sino una big data, o diferentes formas de envasar el esfuerzo de millones de personas mediante algoritmos hechos también por personas, pero no es algo en sí mismo. Y esto es cálculo, no es inteligencia y mucho menos pensamiento. En tercer lugar, la singularidad no existe sino en la imaginación, ya que los procesos biológicos y culturales han sido graduales y constituidos por puntuales casos repentinos revolucionarios sintetizados con largos períodos de equilibrio estático en dichos cambios.

¿Cómo ver desde la bioética al transhumanismo como exacerbación biotecnológica y cuál su neutrlización para retomar el equilibrio perdido?

Esta pregunta es la que puede retornar el equilibrio del hombre exacerbado mencionado en las respuestas anteriores, constituyendo espacios de debate académico en materia axiológica más su divulgación, dando luz y escindiendo la presente falaz sinonimia entre lo biotecnológicamente posible y lo bioéticamente aceptable, donde esto último devino en un mero correlato de lo primero. Un espacio donde se evalúen con rigor académico determinadas cuestiones o posibilidades técnicas considerando el conjunto de normas axiológicas y actitudes de carácter conductivo, predominante en una sociedad o en una fase histórica dada, cuyo cimiento es filosófico- religioso. De hecho, estos dos últimos son los marcos que proporcionan las categorias conceptuales, formas de pensamiento, premisas básicas y procedimientos de una cultura determinada, para evaluar las normativas conductuales en un campo de estudio o área de experiencia. Estos espacios, en los cuales no haya lugar para monolíticas coyunturas tecnocráticas, en términos prácticos, hará que todo deseo del hombre, por más noble que pueda considerarse, incluso el de remediar o aliviar sufrimientos, no constituya per se su máxima o imperativo categórico a partir de lo cual construye su deontología, evitando que el hombre devenga en su propio instrumento manipulándose en pos del cumplimiento de su apetito desiderativo. Porque esto fue lo que hizo surgir la ética del self, un homo incurvatus in se conformando una cultura escénica, donde se simula, se ficciona caprichosamente una fenomenologia que contrasta con la patencia de la realidad. Una cultura escénica, en la cual, bajo el omnímodo imperio del deseo, la mera opinión se convierte en palabra autorizada y la ocurrencia desiderativa ocasional, episódica y fragmentaria deviene en principio rector. Todo ello revestido de un pretendido y oportuno racionalismo o cientificidad, conformando la base para regular conductas individuales y sociales consolidándose desde el Estado, legislando en función de una imaginaria respecto de la propia existencia y decretando en función de apariencias y distorsiones, como si ello fuera lo manifiesto por la misma flagrancia del acto evidente. 
Así, el debate bioético, precisamente sobre el limite entre lo técnicamente posible y lo conductivamente aceptable, no reside en una lucha entre una supuesta anuencia o tolerancia infinitamente maleable revestida de racionalidad y progresismo, versus una tan dogmática como la anterior pero ahora supuesta intransigencia cruel basada en la oposición religiosa y conservadora a las novedades en tecnología médica. Más bien, radica en la posibilidad de conocery analizar, metodológica y sistemáticamente, las diferentes concepciones axiológicas constituyentes de nuestra sociedad y determinar si es posible, un mínimo de principios en común para un espacio de debate bioético.

Desde la filosofía, las dos escuelas más importantes en este tópico plantean similarmente un determinismo tecnológico, expresión utilizada por Karl Marx, para quien la fuente del moderno desarrollo tecnológico radica en la competencia salvaje e inescrupulosa respecto de toda variable fuera de la maximización de ganancias, núcleo de la sociedad capitalista. La tecnología así, posee una lógica y dinámica propia e interna no susceptible de modificar en su raíz, salvo por un cambio radical de estructura socio-económica y política.

Jacques Ellul, aunque no marxista, plantea bajo una cierta visión del materialismo histórico severas críticas al sistema circular realimentado entre la tecnificación social y las consecuencias en el modo de vida y las ideologías. No sólo dificultando la emancipación del hombre, sino incluso camuflándola con idearios progresistas que, bajo el sempiterno lema de libertad, felicidad y bienestar a cualquier precio, encubren el yugo de la tecnología modificando consciencias y desarrollando corrientes y tendencias a tales fines, demandando a su vez la producción y consumo de nuevos medios técnicos para satisfacerlas. Ante este modo tecnológico de vida y consciencia como disciplina de masas, Ellul propone un imprescindible fortalecimiento de la conciencia ascética individual restaurando valores que la sociedad tecnificada ha derrumbado. Y esto es por cuanto la tecnología no tiene una finalidad axiológica a la cual se someta, sino que está sujeta a un imperativo racional de eficiencia, donde todo puede ser medio para otra cosa. Básicamente, se trata de un esclavizante sistema circular entre tecnología y apetito desiderativo, el cual sólo encuentra su solución de continuidad en el "puedo pero no quiero", reconquistando el terreno de la ética.

Similarmente, Hans Jonas, desarrolla su principio de la responsabilidad bajo la concepción que la naturaleza puesta al servicio del hombre mediante la tecnología, crea una relación de incumbencia por cuanto aquella se encuentra bajo el poder de éste. No obstante, el abuso de la intervención tecnológica en la naturaleza en general y en la humana en particular, haciendo de ambas un material susceptible de ser alterado radicalmente, devino en el dominio de la tecnología subyugando a un hombre, quien habiente de un tremendo poder basado en el conocimiento y la capacidad tecnológica casi escatológica, se encuentra en crisis por no tener marco de orientación en un mundo que pretende despojarse de toda ética y marco axiológico tradicional. En este sentido, el intervencionismo y la manipulación tecnológica cuyos logros por su propia dinámica tienden a sistematizarse, provocan alteraciones duraderas y consecuencias imprevisibles hasta de la propia condición humana, y por ello demanda una ética no sólo personalista sino integradora de la propia naturaleza. De modo contrario, el hombre claudica esclavizado a aquel sistema. Pero para restablecer la responsabilidad es menester la consciencia y el remordimiento, precisamente aquello que ha corroído el imperativo tecnológico, eliminando al sujeto humano como tal en provecho de un nuevo determinismo. Es debido a dicha responsabilidad que la tecnología podría reubicarse en una posibilidad aplicativa o conductiva, sin devenir inmediata y simplemente por su primicia, en obligatoriedad consumada como nueva referencia deóntica.

Para ambos filósofos, uno cristiano y otro judio, los actuales marcos investigativos dependen de instituciones tecno-burocráticas cuyos resultados no son objeto de reflexión crítica, su praxis no es objeto de la deliberación ética, y se transforman casi inmediatamente por cuestiones de mercado en reglas impuestas a la sociedad conduciéndola ciegamente a un poderoso orden transformador. 
pero destituido de eticidad exhortativa y axiología coercitiva. Nuevamente se concluye en que la posibilidad técnica devino en la esencia del poder que manifiesta una verdad que debe ser acogida como una nueva naturaleza. Así, se concretó de forma bestial y extensiva la transformación de mentalidad y espíritu por los medios instrumentales y la producción, donde hoy más que nunca toma plena vigencia el ejemplo del campesino, quien más allá de su voluntad deviene en soldado mediante el uso de un arma, y el incentivo en su uso resulta tan poderoso que le es imposible evitar ser soldado a menos que otro se la quite. Y si a ello se le suma el mercado, se crea una artificiosa necesidad por el arma, cuya base es esencialmente el lucro. Este es el verdadero peligro, la tecnología disponible adquirida o consumida por una necesidad artificiosa, deseo o ideología motivada y motorizante en lo comercial, que finaliza gobernando a su tenedor y transforma su mentalidad, a menos que el sujeto fuera lo suficientemente educado y formado no sólo para considerar las consecuencias de sus acciones, así como la de otros, sino también manteniendo una conducta en función de una escala axiológica trascendente a todo marco enajenador.

Desde la religión, estos princípios desarrollados por Ellul y Jonas, evitando el círculo vicioso de la laxitud e imperativo tecnológico, consiste en formularse la divina pregunta del Génesis 4:10 "¿Qué has hecho?" traspasando toda falsa reputación. Porque la presunción termina cuando se debe actuar, dado que aquella nunca puede fingir un acto de genuina grandeza como escribir tratados, pacificar pueblos, monoteizar civilizaciones, o más moderna y coyunturalmente traer justicia, verdad, seguridad y bienestar a los ciudadanos. Aquella fundacional pregunta ¿qué has hecho?, imprime una primigenia responsabilidad mutua entre individuos, luego extendida a la del pueblo para así, identificar los actos del individuo con los hechos de una nación.

Es por todo ello que la religión así como la ética en tanto filosofía práctica sufren la actual denostación en favor de un monolítico imperativo tecnocrático, produciendo un hombre despojado de toda tradición y que en términos prácticos, deviene en el consumidor ideal, esclavizado a su deseo como máxima a partir de la cual construye su deontología, instrumentándose a sí mismo y manipulándose en pos del cumplimiento de su apetito desiderativo. Por ende, toda evaluación y tesitura sistemática, en este caso en lo bioético. para distinguirla de la mera posibilidad técnica, opinión u ocurrencia desiderativa, conlleva un imprescindible sistema axiológico en el cual y nuevamente las filosofías y las religiones son su propia base y fundamento. Esto es precisamente lo que resuelve el círculo vicioso entre tecnología, consumo y mentalidad, dado que comprende la obligación de aceptar deberes y/o prohibiciones, ninguna de las cuales deviene de la tecnología, sino que dependen de la escala axiológica del individuo o de un colectivo humano. Sólo asi se podrá establecer criterios y políticas públicas en materia de biotecnologia y salud, contribuyendo a la construcción de una sociedad más justa, promoviendo un individuo virtuoso y una ciudadanía de calidad. Aquello que ya desde los tempos biblicos se comanda construir y se denomina en hebreo como una [jevrá metukenet] "sociedad enmendada".

\section{Dirección:}

Evandro Pontel

Pontificia Universidade Católica do Rio Grande do Sul Av. Ipiranga, 6681, Prédio $8,4^{\circ}$ andar, sala 403

Partenon 90619-900

Porto Alegre, RS, Brasil 